\title{
PARAMETRIC WORKFLOW (BIM) FOR THE REPAIR CONSTRUCTION OF TRADITIONAL HISTORIC ARCHITECTURE IN TAIWAN
}

\author{
Y.-P. Ma ${ }^{\text {a, }}$, C. C. Hsu ${ }^{\text {b* }}$, M.-C. Lin ${ }^{\text {c }}$ Z.-W. Tsai ${ }^{\text {b }}$ J.-Y. Chen ${ }^{\mathrm{d}}$ \\ ${ }^{a}$ Dept. of Urban Planning and Spatial Information, Feng Chia University, Taichung, Taiwan - yupin.ma@gmail.com \\ ${ }^{\mathrm{b}}$ Dept. of Spatial Design, Kun Shen University, Tainan, Taiwan - (cheng1881, joloplus323)@gmail.com \\ ${ }^{\mathrm{c}}$ Dept. of Architecture, National Cheng Kung University, Tainan, Taiwan - jean.8909@hotmail.com \\ d Dept. of Architecture, Taoyuan Innovation Institute of Technology, Jhongli, Taiwan - joy.chen4@gmail.com
}

Commission VI, WG VI/4

KEY WORDS: Historic Architecture, Taiwanese Traditional Building, Parametric Workflow, BIM, Repair Construction

\begin{abstract}
:
In Taiwan, numerous existing traditional buildings are constructed with wooden structures, brick structures, and stone structures. This paper will focus on the Taiwan traditional historic architecture and target the traditional wooden structure buildings as the design proposition and process the BIM workflow for modeling complex wooden combination geometry, integrating with more traditional 2D documents and for visualizing repair construction assumptions within the 3D model representation. The goal of this article is to explore the current problems to overcome in wooden historic building conservation, and introduce the BIM technology in the case of conserving, documenting, managing, and creating full engineering drawings and information for effectively support historic conservation. Although BIM is mostly oriented to current construction praxis, there have been some attempts to investigate its applicability in historic conservation projects. This article also illustrates the importance and advantages of using BIM workflow in repair construction process, when comparing with generic workflow.
\end{abstract}

\section{CONSERVATION AND APPLICATION TREND OF HISTORIC ARCHITECTURE}

In addition to cultural values, historic buildings also mean a significant reference for designing new buildings. A historic building might be damaged by weather or human-made factors to some extent. Therefore an appropriate restoration job at some point is needed for prolonging its life cycle. Regulations such as Cultural Heritage Preservation Act were made to ensure that preservation work of historic buildings is carried out prudently due to Taiwan's emphasis on cultural assets in recent years.

Despite preservation work of historic buildings keeps carrying on during the five-hundred-year history of Taiwan, there often were gaps in the look of buildings before and after the restoration. Probably because of the scarcity or loss of ancient documents, most of the design drawings are 2D, and the incomplete restored records were supplemented by oral and written description as well as some pictures, which resulted in the uncertainty and difficulty of their outcomes.

Moreover, the early techniques for restoring traditional buildings were mainly contributed by craftsmen while every job of design and construction was put together and executed by those craftsmen with different skills. As a result of the modifications of relevant regulations as well as the intervention of modern construction system, construction works now rely on specialization and are no longer led by craftsmen while the craftsmanship that is based on craftsmen's experience and memories is also fading. The heritage of restoration techniques may have been lost.

Because of the changes to the participants of the restoration, the skills and tools of design drawings, and the methods of information conservation in the complicated restoration and conservation of historical records, it would thus be a trend to introduce architectural information sharing and digitalization into the preservation of historic buildings.

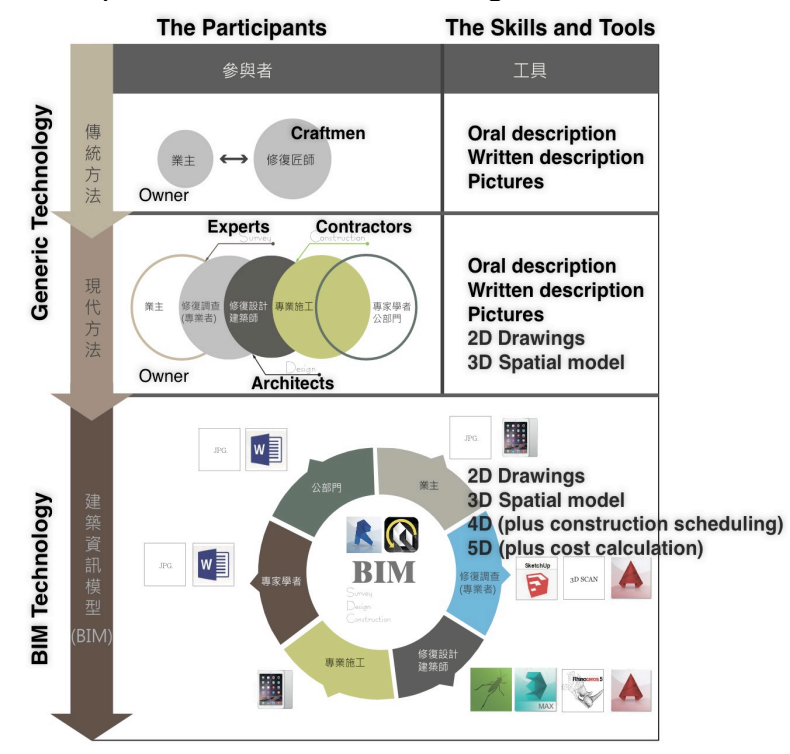

Figure 1. Conservation and application trend of historic architecture

\subsection{Change to the Participants of Restoration}

The construction and restoration works of traditional buildings in the early days of Taiwan were mainly designed and constructed by craftsmen. As a result of the modifications of relevant regulations as well as the intervention of modern construction system, craftsmen nowadays no longer lead the construction works. However, the outcomes of restoration vary with the professional trainings and ideas of participants. No feedback will be acquired during the process if the restoration is implemented inappropriately. The life cycle of a historic 
building can be prolonged if digitalization is introduced into the preservation of traditional buildings while contributing to architectural education and digital archives.

\subsection{Change to the Skills and Tools of Design Drawings}

$2 \mathrm{D} / 3 \mathrm{D}$ design drawings are essential for a restoration work. It is not easy to gather statistics from as well as manage the records of 2D data of most traditional architectural drawings made by drawing papers and CAD. Errors and the loss of data often occur in the floor plans, elevations and sections of traditional 3D drawings made by CAD layer by layer which could be reserved without legibility, systematization and continuity. Therefore BIM (Building Information Modeling) is a relatively better solution for the issues. In addition to restoring the original design drawings and data of historic buildings, it can also be applied for making up the loss and the lack of documentation; or for updating, sharing and creating conservation documentation.

\subsection{Change to the Methods of Information Conservation}

For the cultural assets that worth archiving, the digital way of archive and storage has become an alternative opportunity for them to be preserved. There are over $60 \%$ traditional buildings in Taiwan built by timber frame, which has its own logic of name, function, meaning, and construction type. The sequence of knocking down and setting up the frame for restoration works is based on craftsmen's know-how and experience and can be traced to certain extent. However, so far, their linguistic structure is still not easily determined by those engaging in historical heritage. It is crucial for architectural education and digital archive that the valuable know-how can be digitalized and described by a universal digital data format while a digital database of timber frame is established. It would be a significant subject in applying BIM to digital modeling and adding information of elements for historic buildings.

At the moment, the studies in regard to the applications of digital technologies to historic buildings stress on the 3D reconstruction of geometric model or surface model, which is nevertheless not easy to apply due to the incompatibility of data that is resulted from different ways of modeling. It is thus imperative to integrate the preservation works of historic buildings by applying BIM.

This feasibility study that applied BIM to adding information on the timber frame of traditional buildings in Taiwan aims to establish the database of parametric information modeling for historic buildings in order to provide accurate data during restoration process in the future. Digital modeling as well as the data that records the form and decay of components in order to provide the historical data for restoring the objects of the project will create a medical record of building. Updating the information of objects and inputting them into the project as feedback can therefore sustain the original look and values of a historic building.

\section{APPLY BIM IN REPAIR CONSTRCTION PROCESS}

The success of applying BIM to the design and construction of new buildings has been proved by many cases. The BIM creation process can be differentiated between for new and for existing buildings due to varying building information quality, information availability and functionality requirements. Two different engineering works lead to different management processes, steps and ideas-the process of constructing a new building starts from zero, and followed by the construction work based on design drawings from building plan to every details. As an existing building, the restoration work of a historic building starts from existing building plans and onsite investigations to the design drawings and construction works of restoration.

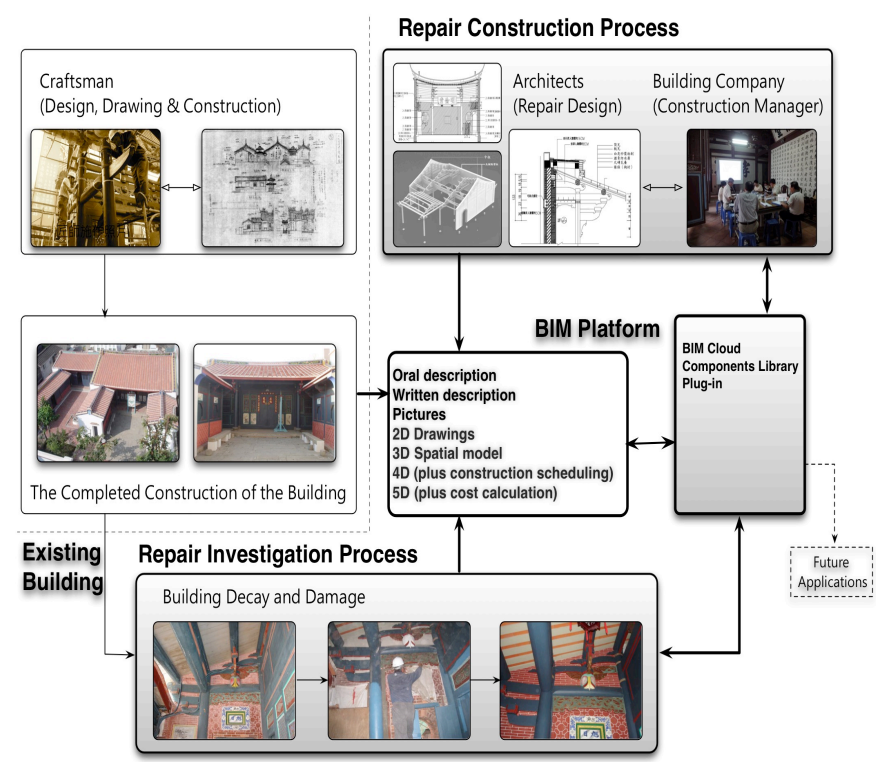

Figure 2. BIM creation workflow for Historic Building Repair Construction

\subsection{The Advantages of Parametric Modeling for the Repair Construction}

There are many advantages in the application of the BIM technology in the restoration of historic buildings:

\begin{tabular}{|c|c|c|}
\hline $\begin{array}{c}\text { Construction } \\
\text { Drawing }\end{array}$ & $\begin{array}{c}\text { Deneric Technology } \\
\text { Negotiation }\end{array}$ & BIM Technology \\
\hline $\begin{array}{c}\text { Technical } \\
\text { Disclosure }\end{array}$ & Drawing & Construction Digit \\
\hline $\begin{array}{c}\text { Construction } \\
\text { Management }\end{array}$ & Process Control & Whole-course Control \\
\hline $\begin{array}{c}\text { Construction } \\
\text { Progress }\end{array}$ & Process Arrangement & $\begin{array}{c}\text { Whole-course } \\
\text { Arrangement }\end{array}$ \\
\hline $\begin{array}{c}\text { Construction } \\
\text { Cost }\end{array}$ & $\begin{array}{c}\text { Drawing-based } \\
\text { Measurement }\end{array}$ & $\begin{array}{c}\text { Software Statistical } \\
\text { Specification }\end{array}$ \\
\hline $\begin{array}{c}\text { Completion } \\
\text { and Delivery }\end{array}$ & Drawing of & $\begin{array}{c}\text { Information Model } \\
\text { Carrier of Historic } \\
\text { Culture }\end{array}$ \\
\hline
\end{tabular}

Table 1. Generic Technology vs. BIM Technology

In digital record: (1) visualization: achieve the $3 \mathrm{D}$ visualization of the design drawings to be restored; (2) presentation of details behind the object's surface: presentation of the internal details of the component, the time records and materials of component restoration, and the records of architectural methods; (3) integration of the information of restored documents.

In data sharing: (4) the design and application of component parameterization; (5) Procedural application of API; (6) the research on and the establishment of the icloud genetic database. 
In data statistics: (7) component structure and material specification; (8) component combination and the framework sequence list.

The study focuses on data recording and sharing and the BIM technology-based component parameterization of historic buildings. Meanwhile, it accumulates group components frequently-used in the design of historic buildings, which can be taken as group components of constant use and can enhance the reutilization of components, so as to increase the efficiency of the restoration design.

\subsection{BIM Creation Workflow}

The BIM creation restoration workflow will go through three stages including investigation, design and construction:

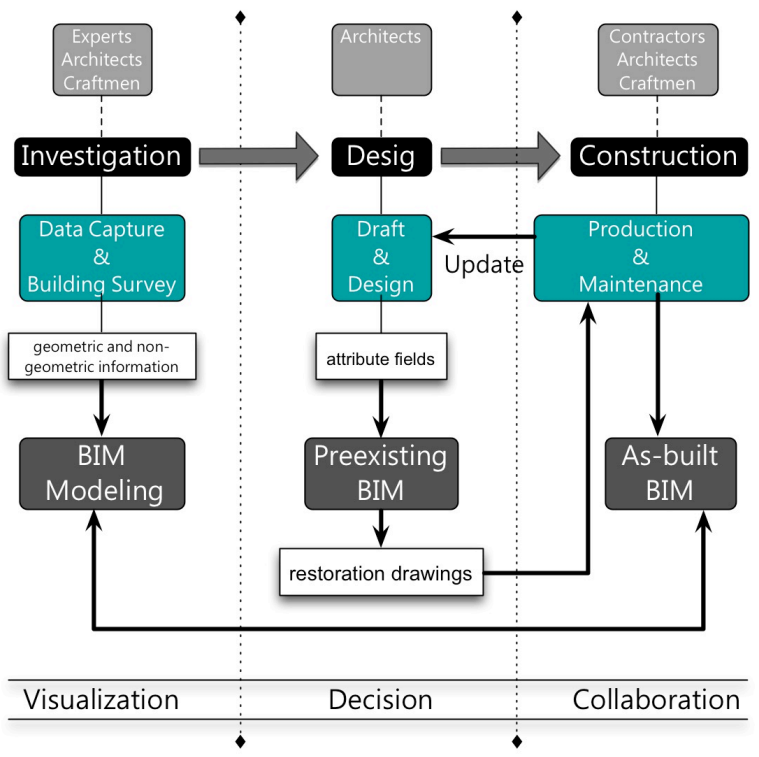

Figure 3. BIM creation workflow for Historic Building Repair Construction

2.2.1 Design Investigation: In Taiwan, more than $80 \%$ of existing timber frame buildings are built before 1965 and mainly do not have a building documentation in BIM format (Y. Arayici,2008). Many existing historic buildings have insufficient, preexisting building documentation and being restored with only simple $2 \mathrm{D}$ hand drawings or perspectives in hands. Without comprehensive drawings and materials, a 3D model is required to be digitalized first to obtain BIM in a "reverse" way for retrieving its original look during the stage of investigation.

Digital technology can be applied for surveying and mapping ahead when BIM is introduced to historic building restoration. However, most studies for the applications of these digital technologies to historic buildings stressed on $3 \mathrm{D}$ reconstruction of geometric model or surface model without data integration for object restoration. Therefore if implemented in practice, costly and mainly manual reverse engineering processes ('points-to-BIM', 'scan-to-BIM') is performed (T. Mill, A. Alt, R. Liias,2013) to gather and model actual building conditions and help recapturing building information.

The following directions can be found in the literature in regard to the techniques transforming data of building elements into $2 \mathrm{D}$ and $3 \mathrm{D}$ visualizations including multimedia animation and virtual reality technologies such as 3D scanning point cloud technology; parametric modeling and 3D modeling (Baik, Boehm \& Robson, 2013; Boeykens, Himpe \& Martens, 2012; Boeykens \& Neuckermans, 2009; Chen, 2008; Chévrier \& Perrin, 2009; Shah \& Mäntylä, 1995; Murphy, McGovern \& Pavia, 2013).

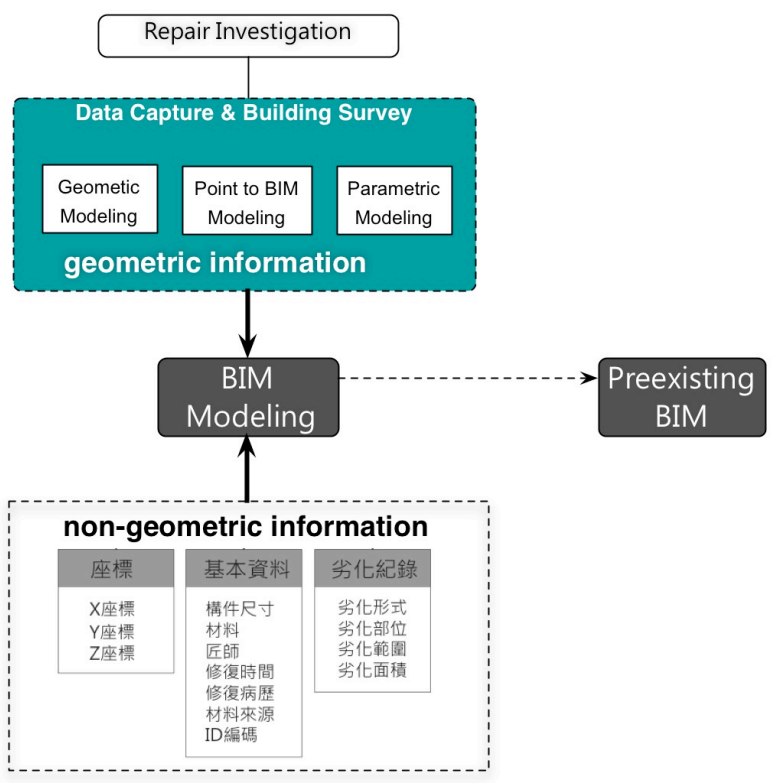

Figure 4. BIM modeling process in repair investigation

2.2.2 Repair Design: The restoration design of historic architecture is led by architects. According to the information gained in the stage of restoration investigation, architects will use digital tools to establish a BIM model and then consider the strategies and methods of the restoration design. Hence, apart from a visualized model, diverse restoration information must be collected in the architectural information model, including restoration methods with or without disintegration, the restoration of intervention level, the methods of component restoration, restoration materials, restoration technicians, and the restoration year.

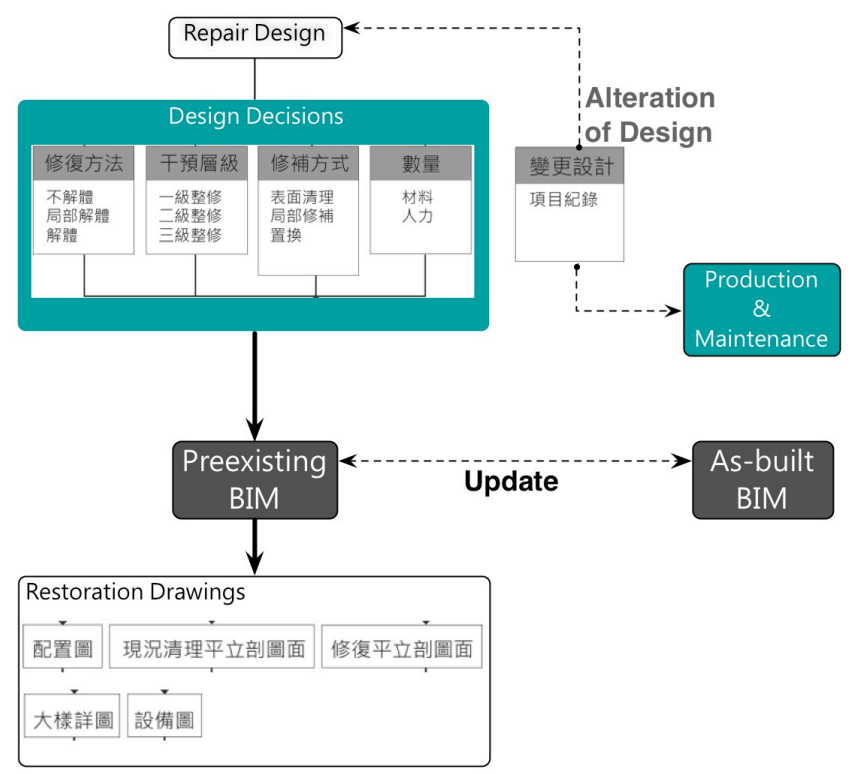

Figure 5. BIM modeling process in repair design decision 
Preexisting BIM model provides 3D (spatial model with quantity takeoff), 4D (plus construction scheduling) and 5D (plus cost calculation) BIM. The information will be combined with the 3D model visualization and the inquiry into the information about restoration. Then, it will be used to present complete restoration drawings, including the configuration drawing, the layout drawing, the facade drawing, the section drawing, the detail drawing and even the equipment drawing, so as to facilitate future restoration and quality inspection.

2.2.3 Repair Construction: After the restoration construction is contracted by the manufacturer, the manufacturer and the technicians will obtain complete and understandable information and drawings through the digital information model to ensure the accuracy of the restoration. Moreover, the information model will be used to establish the restoration process of various aspects, such as the foundation, the brick wall, the wooden framework and the colour decoration on the ceiling.

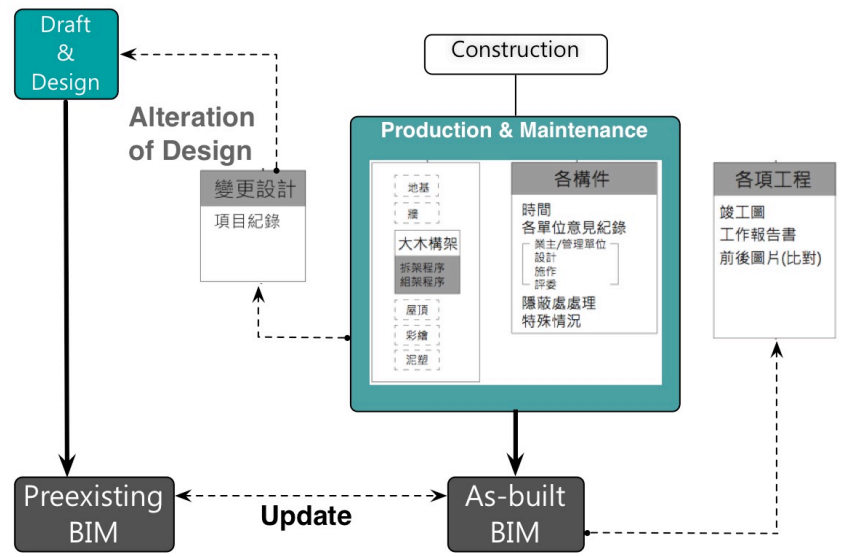

Figure 6. BIM modeling process in repair construction

The professional technicians can gain relevant information according to their needs. If it is necessary to change the design because of new findings or unexpected restoration designs, they can report the information about the change to the information model and accumulate such information as the restoration completion drawing, work reports and the before- and afterrestoration comparison, so as to ensure the completeness and conservation of the final restoration results.

To create an as-built BIM from scratch, geometrical and topological information of building elements has to be gathered, modeled and complemented by semantic property/ attribute information manually. If a reliable data capture technique could provide an as-built BIM at reasonable time and cost, existing buildings could benefit from BIM usage e.g. regarding documentation, visualization or facility management. In this way, the information platform of the restoration of historic buildings can be used for practical, fast and understandable sharing of information.

\section{APPLICATIONS}

In most existing historic buildings, insufficient building information and no available preexisting BIM lead to application that discussed below. The technical platform BIM was applied to historic building restoration in this study. The form of each building element and the information of decay were established to make component object medical records. During the restoration process, all personnel involved was allowed to swiftly check the records of components made for the project through the accumulation of construction data while extracting and updating information as the feedback for the use of design and implementation of historic building restoration next time.

The applications of BIM to the restoration of traditional historic buildings in Taiwan explored by this study comprise three parts:

1. 3D Visualization: the detail behind the object's surface of 3D visualization and component object of design drawings for restoration works;

2. Design and application of parametric object;

3. Integration of conservation documentation: the conservation timeline of component object, the use of materials and the disclosure of techniques.

By targeting the timber frame of traditional buildings in Taiwan, 3D model, parametric object and database of conservation documentation are built for providing more accurate data and conservation documents in order to support the design and restoration of historic buildings as well as improve the efficiency of workforce. The reference for the sequence of constructing timber frame and the treatment of restoration works are also available.

\subsection{Target}

Traditional buildings in Taiwan were built in several construction systems: brick, stone, wood and bamboo and composed of the following parts- footings, structures, openings and roof. Around $60 \%$ of them are wooden buildings with diverse and complicated types of timber frame that functions as the major frame of the building.

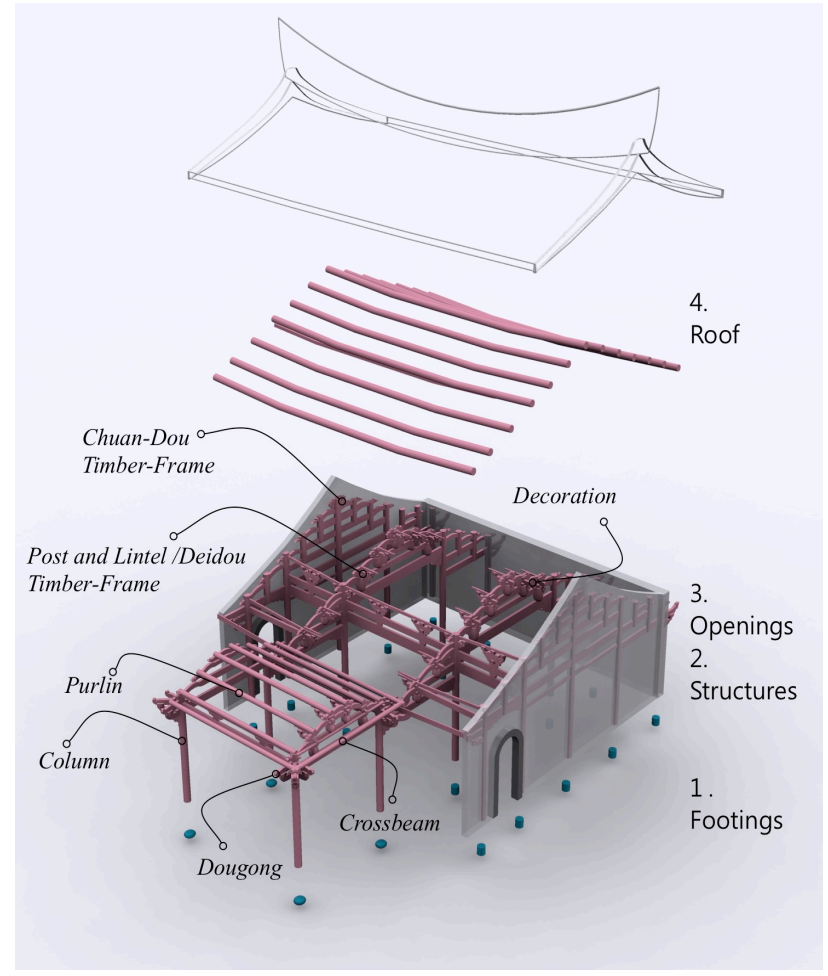

Figure 7. Parametric categories: 1. Footings and vertical structure; 2. Horizontal structure; 3. Openings; 4. Roof structure. Roof and wooden trusses 
With specific meanings for its sequence, the main space is formed by four hypostyle columns in the middle. There are three different construction types formed by vertical columns and columns-Column and Tie Construction; Post and Lintel Construction; and Deidou Construction. The triangle frame piled upon the timber frame functions as the support of the slopes in the front and back of the rooftop. In addition, timber frame can also be distinguished by Carpentry Work and Joinery Work which the former plays the role of carrying the load of the building with elements of Bean, Column, Dougong and Purlin while the latter stands for the wooden elements of architectural décor.

\subsection{From the Survey to the Model}

BIM in this study is applied for integrating the timber frame restoration of historic buildings:

1. It started from the visualization modeling of the basic component objects of timber frame;

2. and followed by using software Revit in parametric modeling of component object;

3. Integrating restoration data and recording the form of each building element as well as the details of decay in every period of time as creating the Object Medical Records for buildings which can be used as reference when restoration work is needed once again.

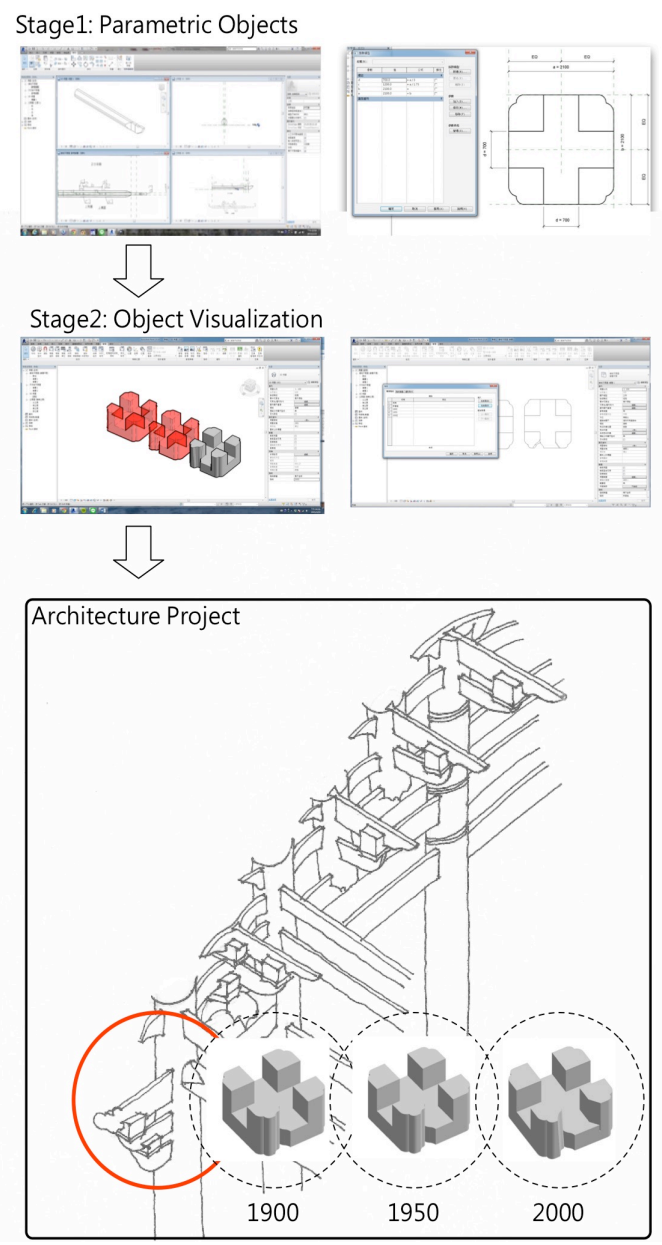

Figure 8. Information Model Process

The designer of the next restoration project is thus able to review previous records and the restoration information of elements in different periods; extract the latest restored elements and update the data; and input them into the project as feedback in order to establish a comprehensive database for historic building restoration.

3.2.1 Object Visualizations: The visualizations the study established would include not only the geometric and surface models but restoration data and results of the objects themselves. The documentation of restoration will also be further integrated for the consequent applications of historic buildings restoration.

3.2.2 Parametric Component Objects: There are three types of BIM: Component Object, Layered Object and Assembly. Our study focuses on Component Object which is created by naming and coding the elements; by entering the size, material of object; the year of construction; the time, method, craftsman and architects for restoration into database as the first step. The next step is to establish parametric component objects for rapidly and accurately executing designs for the follow-up restoration or reconstruction.
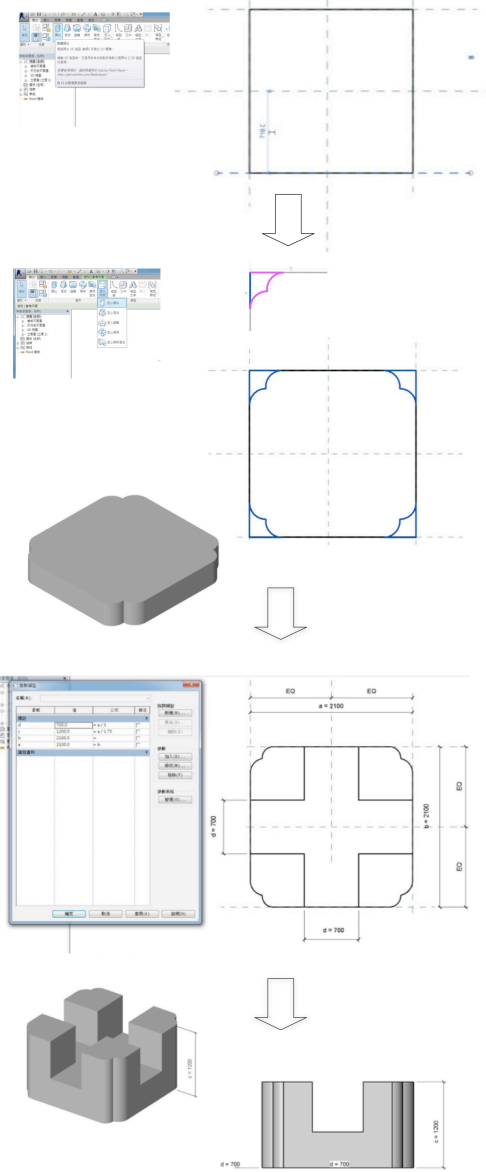

Figure 9. The system of parametric modeling process

The method of establishing components was elaborated by the example of the timber frame of Taiwanese traditional veranda in Figure 9. The 2D/3D visualization drawings for different dimensions of objects could be rapidly made and applied versatilely by selecting elements of timber frame-bean, Gong (one type of beams) and Dou (a connection element); inputting required sizes into boxes and using the functions of Autodesk Revit Architecture to modify the sizes and forms of the objects. 
3.2.3 Data Integration of Restoration Documentation: The restoration documentation in different years will be established in object database for the future reference of next restoration. The options in the field of the year of object restoration can be set with time, content and records of the restoration accordingly as well as be modified during the process of restoration. The restoration team is allowed to review the records of object restoration in different periods; collect previous objects and add current data via BIM.
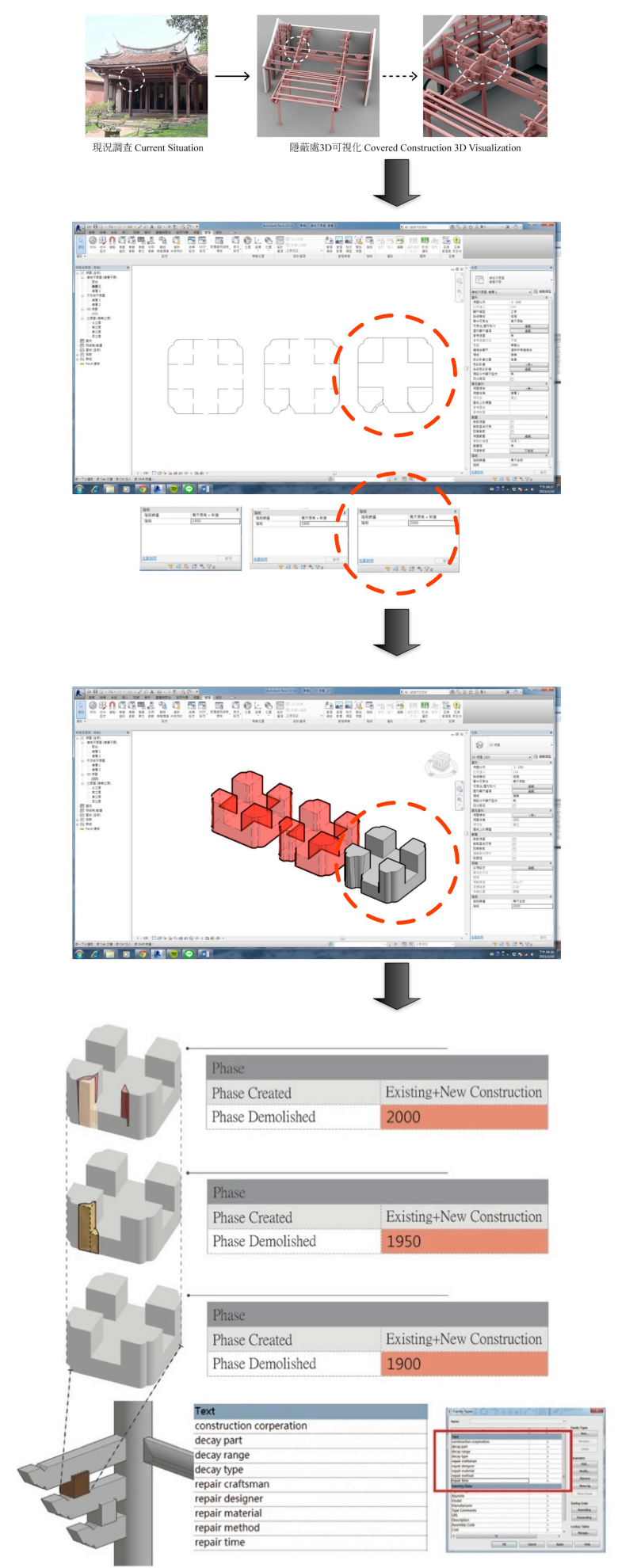

Figure 10. The medical records of object restoration in different periods
In Figure 10, the same element restored in three different periods was layered by $2 \mathrm{D} / 3 \mathrm{D}$ visualization drawings to enable the designer to realize the method, parts, materials, and time used as well as the craftsmen involved in the past restorations while establishing comprehensive records to improve architect's diagnosis and treatment on building elements.

\section{CONCLUSIONS AND FUTURE WORKS}

\subsection{Conclusions}

By introducing BIM into the preservation and restoration of the timber frame of traditional historic buildings in Taiwan, the establishment of visualization model, the design of parametric component objects and the update of the information for object restoration were carried out in this study to increase the reuse of objects, improve the efficiency of restoration design and ensure the outcomes. The following is the result at the fundamental stage of this study:

1. 3D visualization: the display of details behind the object's surface of 3D visualization and component object of design drawings for restoration works.

2. Design of parametric component object: in terms of the geometric information for establishing components of historic buildings, both manual and automatic parametric modes were provided to rapidly modify the size and form of component objects.

3. Integration of conservation documentation: in terms of the non-geometric information, the concept and norm of component object medical records were provided for the reference and applications of another restoration work.

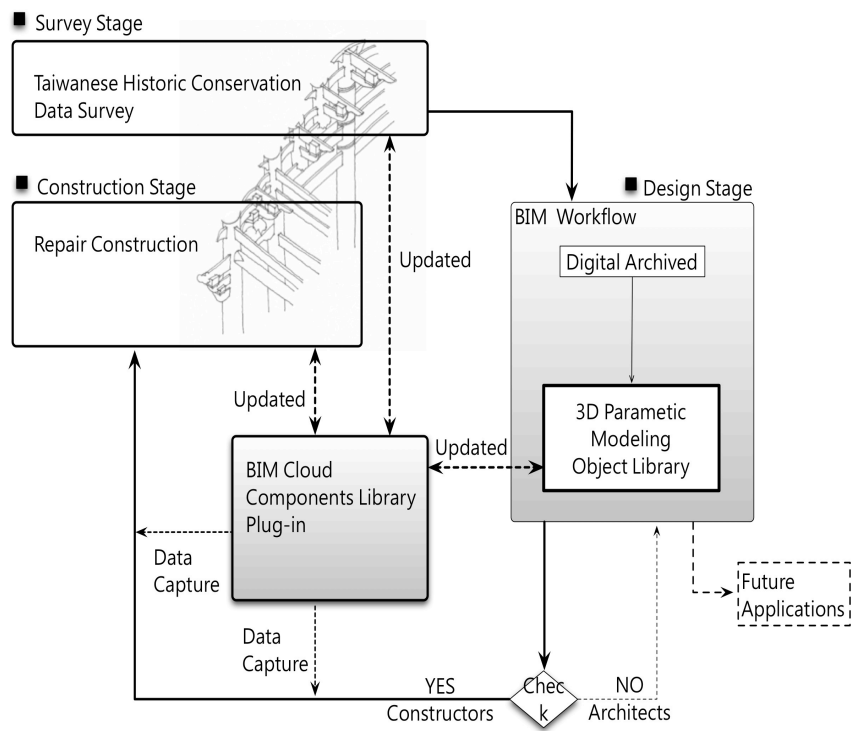

Figure 11. The medical records of object restoration in different periods

\subsection{Future Works}

The restoration of timber frame is particularly labour intensive. Because of the unique restoration techniques and structures of wooden frames in the traditional Taiwanese architecture, the restoration is very complicated and cost-consuming. More often than not, the restoration may entail partial disintegration or general disintegration of the frame (full frame disintegration). 
Each wooden element has to be coded for investigating the damages, joggle joint types as well as the names, resources of materials when carrying out partial dissection, or complete dissection and scaffold dismantling. The top-down sequence of knock-down job needs to be recorded whereas the opposite sequence is found in constructing the timber frame. All these jobs are required for a complete reconstruction in the future. Therefore the discreetness and precision of timber frame restoration is essential for the purpose of prolonging the life cycle of historic buildings.

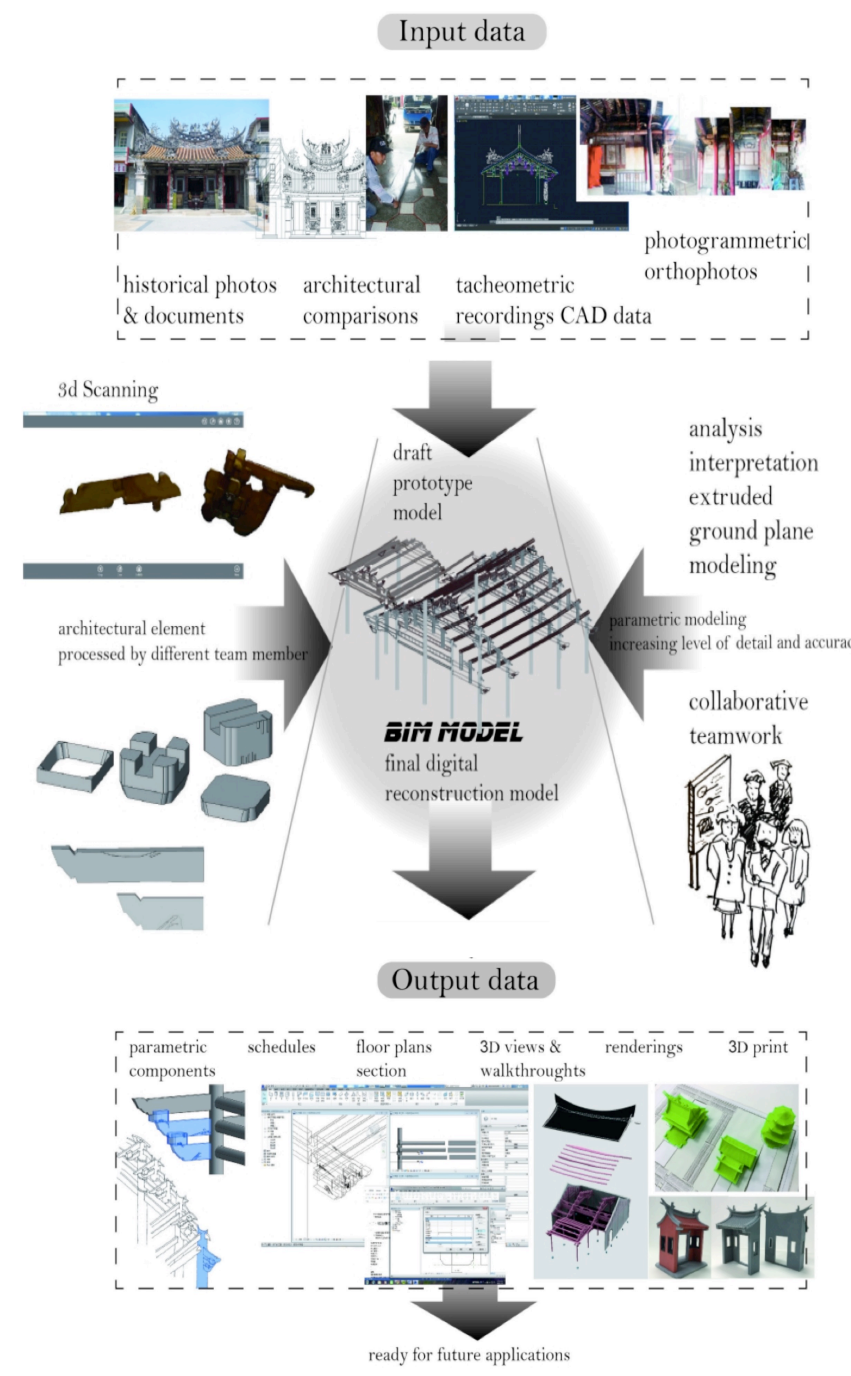

Figure 12. Parametric workflow for the Huji Temple

In the later stage, the restoration of the frame disintegration of the wooden structure of Huji Temple in Tainan will be taken as a research object, and BIM will be applied to build a more complete information platform of the restoration of historic buildings. After components information modeling being completed, the knock-down and set-up of timber frame elements, the establishment of component object library, the application of API procedure as well as the design and development of Plug-in will be the directions of future studies.

\section{ACKNOWLEDGEMENTS}

The authors wish to thank Professor Taysheng Jeng for his valuable comments and Dr. Yo-Hua Tsai for his suggestions on the restoration of ancient buildings and his recommendation of taking the restoration of Huji Temple in Madou as the experiment field. We also thank Architect Chong-Chin Chao for the contributions of the previous works on the restoration of Huji Temple and for the provision of relevant drawings and work progress.

\section{REFERENCES}

Arayici, Y., 2008. Towards Building Information Modelling for Existing Structures, Structural Survey,26.3, 210-222.

Baik, A., Boehm,J. \& Robson, S., 2013. JEDDAH HISTORICAL BUILDING INFORMATION MODELING "JHBIM" OLD JEDDAH-SAUDI ARABIA, Int. Arch. Photogramm. Remote Sens. Spatial Inf. Sci., XL-5/W2,73-78.

Boeykens, S., Himpe C. \& Martens, B., 2013. A case study of using BIM in Historical Reconstruction. The Vinohrady synagogue in Prague, in Proceedings of the 30th International Conference on Education and research in Computing Aided Architectural Design in Europe, Prague, Czech Republic.

Boeykens, S. \& Neuckermans, H., 2009. Architectural design analysis, historical reconstruction and structured archival using $3 D$ models: Techniques, methodology and long term preservation of digital models, In Joining Languages, Cultures and Visions: Proceedings of the 13th International CAAD Futures Conference, 119-132.

Chen, C.-J., 2008. The study on Improved Mechanical Properties of Reinforced Traditional Chuan-Dou Timber Joints in Taiwan, Journal of Cultural Property conservation, $v 1$ (3), pp 5-14.

Chévrier, C. \& Perrin, J.-P., 2009. Generation of Architectural Parametric Components, in T. Tidafi \& T. Dorta, eds. Joining Languages, Cultures and Visions : CAAD Futures. Montréal (Canada): Les Presses de l'Université de Montréal, pp. $105-$ 118.

Eastman, C., 2006. Report on integrated practice university and industry research in support of BIM. G. I. o. T. American institute of Architects.

Fai, S., Graham, K., Duckworth, T., Wood, N., Attar, R., 2011. Building Information Modelling and Heritage Documentation, 23rd International Symposium, International Scientific Committee for Documentation of Cultural Heritage (CIPA), Prague, Czech Republic

Fai, S., Duckworth, T., Graham, K., Wood, N., 2011. Building Information Modelling and the Conservation of Modern Heritage, The 24the World Congress of Architecture, Union International des Architects (UIA), Tokyo, Japan.

Garba, S. B. \& Hassanain, H. M., 2004. A review of objectoriented cad potential for building information modelling and life cycle management, 1st ASCAAD International Conference, e-Design in Architecture. KFUPM, Dhahran, Saudi Arabia. 
Hsu, C.H., Ma, Y.P., Chen, J.Y., Tsai, Z.W., Lin, M.C., 2015. Using BIM In TAIWAN Historical Wooden Building Conservation". The 8th International Conference on Planning and Design (ICPD) (May 25th - 28th, 2015, NCKU, Taiwan.)

Murphy, M., McGovern, E. \& Pavia, S., 2013. Historic Building Information Modelling. Adding intelligence to laser and image based surveys of European classical architecture, in ISPRS Journal of Photogrammetry and Remote Sensing, Elsevier, Vol. 76, pp. 89-102.

Mill, T., Alt, A., Liias. R., 2013. Combined 3D building surveying techniques - terrestrial laser scanning (TLS) and total station surveying for BIM data management purposes, $J$. Civ. Eng. Manag. (iFirst 1-10, Published online: 24 Oct 2013).

Russell, P. \& Elger, D., 2008. The Meaning of BIM, Architecture in Computro, Proceedings of the 26th eCAADe Conference, Antwerpen, September 2008, 531-536.

Shah, J. J. \& Mäntylä M., 1995. Parametric and Feature-based CAD/CAM: Concepts, Techniques, and Applications, Published by Wiley-Interscience. 